AEA, LXXVIII, 2005, 312, pp. 397 a 412. ISSN: 0004-0428

\title{
ESCULTORES ACADÉMICOS DEL SIGLO XVIII EN EL DICCIONARIO DE CEÁN BERMÚDEZ. NUEVAS ADICIONES (II)
}

\author{
POR \\ VIRGINIA ALBARRÁN MARTÍN \\ Universidad Complutense de Madrid
}

En el número 310 de A.E.A. dimos a conocer aquellos artículos relativos a los escultores académicos desde la letra $A$ hasta la $E$ que fueron suprimidos en el momento de publicación del Diccionario de los más ilustres profesores de las Bellas Artes en España de Juan Agustín Ceán Bermúdez. Continuamos en esta segunda entrega con los correspondientes desde la letra $F$ hasta el final. La escasez de bibliografía sobre algunos de los artistas mencionados convierte a estos documentos en fuentes de primer orden al contener datos en gran parte inéditos.

Palabras clave: Ceán Bermúdez. Real Academia de Bellas Artes de San Fernando. Biblioteca Nacional. Escultores. Siglo XVIII.

In A.E.A. number 310 we presented Ceán Bermúdez's information on sculptors whose surnames begin with the letters $A$ through $E$, entries which were finally not included in his Diccionario de los más ilustres profesores de las Bellas Artes en España (1800). In this second part, we continue from $F$ to $Z$. The scarcity of bibliography concerning some of these artists means that these documents are of prime importance, given that they frequently include unpublished information.

Key words: Ceán Bermúdez. Royal Academy of Fine Arts of San Fernando. National Library. Scuiptors. 18 th Century.

En agosto de 1799 la Real Academia de Bellas Artes de San Fernando, al hacerse cargo de la edición del Diccionario histórico de los más ilustres profesores de las Bellas Artes en España de Juan Agustín Ceán Bermúdez, decide suprimir los artículos pertenecientes a los artistas vivos en el momento de la impresión '. Estos documentos, conservados en la Biblioteca Nacional, no habían sido publicados hasta ahora a pesar de su interés pues gran parte de ellos contienen noticias inéditas en relación a un nutrido grupo de artífices ${ }^{2}$. Si bien, y debido al número de artículos encontrados, se ha optado por exponer en estas dos primeras publicacio-

\footnotetext{
${ }^{1}$ La problemática que rodeó a la publicación del Diccionario de Ceán Bermúdez se comenta con mayor detenimiento en el primero de los artículos dedicađos a esta cuestión: Albarrán Martín, V.: «Escultores académicos del siglo xviII en el Diccionario de Ceán Bermúdez. Nuevas Adiciones (I)», A.E.A., Madrid, tomo LXXVIII, n. ${ }^{\circ}$ 310, 2005, pp. 145-162.

${ }^{2}$ Los diferentes artículos, tanto los que finalmente se publicaron como los que fueron suprimidos, se conservan en distintos expedientes de la citada institución y aparecen mencionados ya en Santiago Páez, E.: El gabinete de Ceán Bermúdez: dibujos, manuscritos y estampas de la Biblioteca Nacional, Biblioteca Nacional, Madrid, 1997, p. 14.
} 
nes la información sobre los escultores académicos, ámbito en el que aún queda mucho por trabajar y a cuyo conocimiento pretendemos contribuir con la divulgación de estos escritos.

En la primera parte se incluyeron aquellos dedicados a Manuel Adeba Pacheco, Alfonso Giraldo Bergaz, Isidro Carnicero y José Esteve, escultores que ya con anterioridad habían sido objeto de distintos estudios, por lo que los documentos de Ceán, más que incorporar datos nuevos, permiten aclarar cuestiones que invitan a una revisión de la obra de estos artistas. En cambio, en esta segunda entrega se presentan los correspondientes al resto de escultores académicos del siglo XVII, artífices cuya actividad está, en general, por descubrir, como demuestra la escasa bibliografía especializada que existe al respecto, por. lo que sus articulos resultan de singular interés al contener noticias desconocidas hasta el momento.

Al igual que en la primera de estas publicaciones, dichos artículos se presentan comentados y comparados con aquellas referencias bibliográficas que consideramos más relevantes, intentando a su vez configurar el punto de partida para la realización de un análisis en profundidad sobre la trayectoria de cada uno de los artistas.

\section{ARTÍCULOS COMENTADOS ${ }^{3}$}

«Folch (D. Jayme) escultor ${ }^{4}$

Nació en Barcelona, donde tomó los principios de su arte. Pasó a Madrid y fue discípulo del Director don Manuel Álvarez. Estubo pensionado en Roma y a su vuelta, en virtud de los adelantamientos que había hecho, la Real Academia de San Fernando le creó su individuo de Mérito el año de 1786. Es Director de la escuela del dibuxo de Granada.

Estando en Roma de pensionado remitió a la citada Academia un baxo relieve hecho por él de su invención que representa la muerte de Séneca a presencia de sus discípulos y dos copias en pequeño del Meleagro y del Fauno cuios originales están en el Capitolio.

Las obras conocidas de su mano son las siguientes:

Granada. Parroquia de San Peơro y San Pablo. Dos estatuas de los santos titulares y dos ángeles para el nuevo tabernáculo.

Parroquia de San Mathias. Un Crucififijo (sic: Crucifijo) del tamaño natural. San Josef con el Niño en los brazos.

Parroquia de San Josef. Dos medallas en el retablo mayor de figuras poco menores que el natural: representan el Nacimiento del Señot y su Epifanía.

Padres Terceros. San Juan Niño en el sagrario de una capilla.

Gaór. Parroquia. Un Jesús Nazareno del tamaño natural.

Guadix. Catedral. En el trascoro, las estatuas de madera imitando a bronce».

A pesar de la reducida extensión de este artículo, Ceán proporciona noticias relativas a la producción pública del escultor que no figuran en las obras de Ossorio y del Conde de la Viñaza, los cuales, por otra parte, únicamente incorporan un dato nuevo respecto al texto del anterior y que es la realización del sepulcro y la estatua del Arzobispo don Juan Manuel Moscoso en la capilla de San Miguel de la Catedral de Granada ${ }^{5}$. Tampoco Pardo Canalís añade

\footnotetext{
${ }^{3}$ Las normas de trascripción utilizadas en esta ocasión son las mismas que en el primer artículo: se ha optado por una trascripción histórica de los documentos, respetando la grafía original de los textos y manteniendo las normas actuales en relación a las mayúsculas y a los signos de puntuación y acentuación. Con las abreviaturas se aplica la norma general de desarrollarlas, sin embargo, el «Don» que precede al nombre de los artistas al comienzo de cada artículo se ha dejado tal cual por ser ésta la fómmula que el propio Ceán mantıvo en su Diccionario.

${ }^{4}$ BN, Mss. 21.455, hoja 47.

${ }^{5}$ Ossorio y Bernard, M.: Galería biográfica de artistas españoles del siglo XIX, Imprenta de Ramón Moreno, Madrid, 1868-1869, p. 249; Viñaza, Conde de la: Adiciones al Diccionario histórico de los más ilustres profesores de la Bellas Artes en España de Don Juan Agustín Ceán Bermúdez, Tipografía de los Huérfanos, Madrid, 1889 - 1894, p. 198. Al igual que hizo Ceán en su Diccionario, en esta ocasión el Conde de la Vińaza cita las fuentes utilizadas para confeccionar su escrito dedicado a Folch y dice haberse basado en las actas de la Real Academia de San Fernando y en referencias particulares, sin embargo, salvo insignificantes modificaciones, parece reproducir, de nuevo, el texto de la obra de Ossorio.
}

AEA, LXXVIII, 2005, 312, pp. 397 a 412 
mayor información pues sólo señala la participación del artista en la segunda clase de escultura en el concurso de 1778 y la pensión obtenida en 1779 junto con José Guèrra para continuar sus estudios en Roma ${ }^{6}$.

Será Rafols quien de a conocer datos más concretos sobre el escultor ${ }^{7}$. De acuerdo con este autor, nació Folch en 1755, recibiendo su primera formación artística en la Escuela de Nobles Artes de la Junta de Comercio de Barcelona, bajo la dirección de Francisco Tramulles y Carlos Grau. En 1771 pasaría a la Real Academia de Bellas Artes de San Fernando, donde consiguió la mencionada pensión a Roma que disfrutaría durante siete años ${ }^{8}$. Según Azcúe, dicho período se extiende entre 1779 y 1786 , momento en que es nombrado Académico de Mérito 9 .

Posteriormente sería designado Director de Escultura de la Escuela de Nobles Artes de Granada -lo que coincide con la información facilitada por Ceán- pasando a Barcelona en 1803, siguiendo a Rafols ${ }^{10}$ y en 1805 , según Azcúe. Esta autora comenta además que el escultor estuvo en dicha ciudad hasta 1809 , regresando de nuevo entre los años de 1814 y $1821^{11}$.

De la obra ejecutada por Folch, menciona Rafols la estatua del Arzobispo Moscoso de la catedral de Granada, el relieve de la Muerte de Séneca, el Meleagro y el Fauno ya citados por Ceán y un Marte descansando al que no se había aludido hasta el momento pero que podría identificarse con el Efebo con un pie sobre una roca que indica Azcúe y que incluye en su catálogo junto a un modelo para una fuente que atribuye también al escultor ${ }^{12}$. Sin embargo, todas estas realizaciones se corresponden con la actividad del artista en el ámbito de la Academia de San Fernando, sin que tengamos conocimiento de ningún otro estudio donde se refiera el resto de la producción de Folch, pudiendo considerarse el escrito de Ceán como el más extenso conservado en relación a este aspecto.

Finalmente, añade Rafols que al entrar las tropas de Napoleón en España, el escultor renunció a su cargo ante la negativa de jurar al Gobierno del Emperador y que, tras unos años de dificultades, Fernando VII le restituiría en sus funciones. Falleció el artista en el año 1821.

\section{«Guerra (D. Josef) escultor ${ }^{13}$}

Nació en el pueblo de San Vicente de Arévalo, diócesis de Ávila, el año de 1756. Su aficción a la escultura le traxo a Madrid en busca de su tío don Francisco Gutiérrez, que le enseñó su profesión. Con tan buena escuela y la continua asistencia a la Real Academia de San Fernando logró a los veinte y dos años de edad el primer premio de la segunda clase en el concurso de 1778.

Después de haber estado seis años pensionado en Roma, de donde remitió a la dicha Academia un baxo relieve original que representaba al Señor Difunto con acompañamiento de ángeles, dos copias, la una en

\footnotetext{
${ }^{6}$ Pardo Canalís, E.: Escultores del siglo XIX, CSIC, Madrid, 1951, p. 47.

7 Rafols, J.F.: Diccionario biografico de artistas de Cataluña. Desde la época romana hasta nuestros días, tomo I, Editorial Millá, Barcelona, 1951, p. 441. Posteriormente, Morales y Marín, J. L.: «Escultura española del siglo xviI» en Arte español del siglo XVII, Summa Artis, tomo XXVII, Espasa-Calpe, Mađidi, 1994, p. 440, recoge información similar aunque omite algunas de las obras mencionadas por Rafols.

${ }^{8}$ Urrea indica que los estudios académicos del escultor fueron costeađos por el obispo de Jaén, aunque nada más refiere sobre la cuestión. Urrea, J.: «La escultura en la Corte, 1780-1800» en Tolsá, Gimeno, Fabregat. Trayectoria artística en España. Siglo Xvil, Generalitat Valenciana, 1989, p. 132.

${ }^{9}$ Azcúe Brea, L.: La escultura en la Real Academia de Bellas Artes de San Fernando. Catálogo y estudio, Real Academia de Bellas Artes de San Fernando, Madrid, 1994, p. 289.

${ }^{10}$ Ráfols, J.F.: Op. Cit., p. 441.

${ }^{11}$ Azcúe Brea, L.: Op. Cit., p. 289.

${ }^{12}$ Ibidem, pp. 288-291. Según la autora, este modelo de fuente con Cibeles y los principales ríos de España es considerado por Juan José Martín González como la composición más lograda deI escuitor. Martín González, J.J.: «La escultura de la R.A.B.A.S.F. a través de los Inventarios y Catálogos», Seminario de Estudios de Arte y Arqueología, Valladolid, 1991 , p. 64.

${ }^{13}$ BN, Mss. 21.455, hoja 64.
} 
pequeño del grupo de Psiquis y Cupido que está en el Capitolio, y la otra de mayor tamaño del Neptuno de Bernini que para en la Villa Negroni, todo de su mano, fue nombrado Académico Supernumerario del citado cuerpo.

La estatua de San Eugenio en el nuevo retablo mayor de la parroquia de San Ginés de Madrid y el ángel que está en el propio lado y una estatuita de Nuestra Seŕora de la Paz en una capilla de la iglesia de los capuchinos de la Paciencia, manifiestan el mérito y habilidad de este profesor, de quien esperamos mayores obras según su buena aplicación. También es de su mano un Crucifijo que está en el altar del panteón de la Escuela pía del barrio de Avapies.»

De nuevo encontramos diferencias destacables entre los datos proporcionados por los distintos autores. Ossorio y el Conde de la Viñaza facilitan información semejante procedente, según éste último, de las actas de la Academia de San Fernando, por lo que únicamente citan la producción del escultor en relación con la mencionada institución, prescindiendo del resto de la obra pública ejecutada por el artista y que, en cambio, es referida por Ceán. Del mismo modo, solamente éste alude al parentesco del escultor con Francisco Gutiérrez y al nombramiento de Guerra como Académico Supernumerario, pero no llega a incluir, al contrario que los anteriores, y debido al momento de publicación del Diccionario, su designación como Académico de Mérito de dicho cuerpo en 1803.

Serán los estudios de Serrano Fatigati y de Pardo Canalís los que aporten datos más significativos sobre este escultor que, según parece a tenor de la documentación facilitada por estos autores, tardó bastante en ser reconocido. A través de uno de los memoriales redactados por Guerra, y que está fechado en 1803, conocemos la precaria situación en que se encontraba el artista hasta su nombramiento como individuo de Mérito de la Academia de San Fernando ${ }^{14}$. Siguiendo el documento, el escultor se lamenta de que, tras haber obtenido una formación privilegiada con su tío Francisco Gutiérrez, de haber conseguido premios tanto en la citada Academia como en la del Campidoglio de Roma ${ }^{15}$ y de haber dado sobradas muestras de su adelantamiento por medio de los trabajos realizados y de su buena conducta, la institución madrileña únicamente le había concedido, en 1786, el título de Académico Supernumerario, a diferencia de sus propios compañeros, nombrados Académicos de Mérito, y que, después, al recurrirlo en 1802, le habían dicho que debía seguir los medios establecidos como si de un artista desconocido se tratase. Por esta causa, que considera casi un agravio, pedía se revisase su petición y enviaba para ello la lista de obras que había ejecutado hasta el momento y que Serrano Fatigati reproduce. Examinada la situación por Pedro Michel y por Joaquín Aralí, declararon éstos que hallaban razones suficientes para conceder a Guerra lo que solicitaba, de modo que lo sometieron a votación en Junta, siendo la misma complicada pues sería nombrado Académico de Mérito por un solo voto de diferencia ${ }^{16}$.

De las obras enumeradas en la mencionada lista, pudo Ceán conocer la mayoría de ellas dada la fecha del documento, no obstante, únicamente coinciden en las copias de Cupido y Psiquis, del grupo de Neptuno y del relieve del Cristo Difunto, enviadas desde Roma, y la estatua de San Eugenio en el retablo mayor de la parroquia de San Ginés. Remitidas desde Roma se refieren, además, «una copia del Torso de Belvedere», «Un San Francisco de Paula, copia del Vaticano de Maini», «Una copia de un bajo relieve del dicho Maini», «Un grupo de Santa Teresa con un ángel, copia del mismo», «Un bajo relieve de invención de Cristo cuando da

\footnotetext{
${ }^{14}$ Serrano Fatigati, E.: «Escultura madrileña desde mediados del siglo Xv hasta nuestros dias», B.S.E.E., Madrid, tomo XVIII, 1910 , pp. $278-280$.

${ }^{15}$ Según Martín González, J.J.: «Los escultores de la Real Academia de San Fernando en la época de Carlos ILß en El Arte en tiempo de Carlos II, IV Jornadas de Arte del Instituto Diego Velázquez, C.S.I.C., Madrid, 1989, p. 261, el escultor pasaría a esta ciudad como pensionado en 1784. Sin embargo, Ceán dice que el artista estuvo en Roma seis años, y el propio Guerra, en el memorial citado, afirma que regresó a la Corte en 1785, por lo que se habría marchado a disfrutar de su pensión en torno al año 1779 .

${ }^{16}$ Serrano Fatigati, E.: Op. cit., p. 278.
} 
vista al ciego», «Y un Santiago, copia del que está en San Juan de Letrán, de Angel de Rossi», «Una cabeza de un San Jüan Bautista, de invención», «Unia alegoría dedicađa á Carlos III, que representa la estatua pedestre con las cuatro Virtudes á los cuatro ángulos, con dos bajo relieves y dos inscripciones, todo de invención», «Varios dibujos del antiguo y Academias copiadas del natural» ${ }^{17}$. En la actualidad, en la Real Academia de Bellas Artes de San Fernando se conservan las imágenes de San Francisco de Paula, de Santiago el Menor, unos fragmentos de la copia del relieve de Maini que representa a San Francisco de Paula con unos ángeles, el relieve de Cristo Difunto, el de Cristo dando la vista a un ciego y el grupo de Amor y Psiquis ${ }^{18}$. Azcúe añade a este conjunto de obras enviadas desde Roma un grupo de Ángeles transportando el manto de la Virgen y le atribuye, con ciertas reservas, un relieve del Sacrificio de Isaac -que podría ser el presentado al recibir el nombramiento de Académico de Mérito-, un ángel denominado de la Caridad y unos fragmentos de una figura sentada ${ }^{19}$.

En el documento reproducido por Serrano Fatigati se enumera asimismo el resto de la producción localizada en la Corte, también citada posteriormente por Pardo Canalís, quien, además, da a conocer información interesante al respecto, aunque tampoco en esta publicación se menciona la estatua que Ceán llama de Nuestra Señora de la Paz y que sitúa en la capilla de la iglesia de los capuchinos de la Paciencia ${ }^{20}$. En cambio, indica que Guerra seguirá trabajando hasta que se produzca su nombramiento como Teniente Director de Escultura en 1814. El mismo año solicita la plaza de Escultor de Cámara vacante tras la muerte de Pedro Michel, para lo cual envía otra relación donde se registran, junto con la imagen de San Eugenio y el Ángel de la parroquia de San Ginés, ya citadas en el anterior memorial -y de las que se dice que desaparecieron en un incendio-, la terminación de la Fuente de Neptuno, comenzada por Juan Pascual de Mena, el escudo de mármol de Génova en la fachada de la Casa de los Gremios en la calle Atocha y otro de piedra de Colmenar en la Fábrica de Aguardientes y Rosolís, un San Lorenzo para el retablo mayor de la iglesia dedicada al santo -tampoco conservado-, una Virgen del Rosario en el altar mayor del Oratorio de la calle del Olivar, una fuente con Neptuno para el jardín del Conde de Oñate y un trofeo de piedra para la Puerta de los Pozos, ambas igualmente desaparecidas ${ }^{21}$. Comenta Guerra en este mismo escrito que realizó algunas obras más para la Real Academia de Bellas Artes de San Fernando y otras para fuera de la Corte sin concretar cuáles fueron.

El puesto sería otorgado en esta ocasión a Juan Adán, no obstante, Guerra lo vuelve a intentar en 1815, siendo nombrado un año después Ayudante del Primer Escultor de Cámara ${ }^{22}$ y en 1817 Teniente Director del Estudio de la calle Fuencarral. En 1819 solicita a la Academia el nombramiento de Director de Escultura del citado cuerpo, sobre lo cual no hubo resolución alguna ${ }^{23}$. Tres años después fallecería el escultor.

Conocemos datos nuevos sobre la producción de Guerra gracias a los memoriales que presentaba al solicitar algún cargo o nombramiento, como por ejemplo, el tema que desarrolló en el concurso de 1778 de la Academia de San Fernando ${ }^{24}$ o las obras que realizó para la Casa de

\footnotetext{
${ }^{17}$ Ibidem, p. 281. Algunas de estas obras habían sido mencionadas ya por Ossorio y Bemard, M.: Op. cit., p. 317 y por Viñaza, Conde de la: $O_{p}$. cit., p. 247.

${ }^{18}$ Azcúe Brea, L.: Op. cit., pp. 263-273.

19 Ibidem, pp. $270,266,272$ y 273 respectivamente.

${ }^{20}$ Pardo Canalís, E.: Op. cit., pp. 43-48.

2l Ibidem, po. $182-183$.

${ }^{22}$ Ibidem, p. 44. Este cargo lo compartió Guerra con Francisco Elías y fue creado a instancias del escultor José Ginés.

${ }^{23}$ Ibidem. Según Azcúe Brea, L.: Op. cit., p. 265, en ese momento Guerra conseguiría el puesto de Director de Escultura de la Academia, sin embargo, y coincidiendo con Pardo Canalís, la relación de cargos académicos conservado en el Archivo de la Real Academia de San Fernando no registra este dato. En el primero de estos artículos (ver nota 1) ya se comentó la existencia de dicho listado que también se puede consultar por internet.

${ }^{24}$ El tema a representar era: «El rey moro de Granada entrega a San Fernando las liaves de la ciudad de Jaén» y es citado igualmente por Serrano Fatigati, E.: Op. cit., p. 278 y Azcúe Brea, L.: Op. cit., pp. 263-265.
} 
Osuna, documentandose para este lugar la estatua de una Venus que fue terminada por Adán y la escultura de un templo relacionado con esta familia ${ }^{25}$. Sobre el Crucifijo de la Pasión que aparece mencionado en distintos escritos, Pardo Canalís afirma no tener noticia alguna al respecto, en cambio, comenta la existencia de otro que se veneraba en la iglesia de las Escuelas Pías de San Fernando, to que coincide con la información aportada por Ceán ${ }^{26}$. En relación a la Virgen del Rosario del Oratorio de la calle del Olivar, cree que pudo ser una copia de la que Luis Salvador Carmona había tallado con destino al mismo templo ${ }^{27}$. Finalmente, y basándose en la documentación conservada en la Real Academia de Bellas Artes de San Fernando, Pardo Canalís señala que José Guerra habría ejecutado otra serie de obras para poblaciones como Ávila de los Caballeros, Villafranca del Bierzo y Arenas, entre otras ${ }^{28}$.

Algunas décadas después, Nicolau Castro recoge la colaboración del escultor en la realización de cuatro estatuas de gran tamaño que representaban La Iglesia, La Religión y las Sedes de Sevilla y Toledo que formaban parte de la decoración de la monumental portada que se erigió delante de la catedral de Toledo con motivo đe la solemne entrada en su diócesis del Cardenal D. Luis María de Borbón en febrero de $1801^{29}$.

\section{«Michel (D. Pedro) escultor ${ }^{30}$}

Hermano menor de don Roberto Michel, escultor de Cámata de S.M. Nació en Puy de Velay, en el Languedoc, el día 28 de octubre de 1728. Un pintor flamenco su pariente le enseñó los principios del dibuxo con deseo de seguir la pintura que luego se enderezó a la escultura, y para seguir este arte pasó a Lyon, donde halló un buen maestro. Pero sabiendo la buena acogida y estimación que tenía su hermano en Madrid, vino en su busca y llegó a la Corte el día 19 de Junio de 1748.

Don Roberto le envió a dibuxar y modelar a los estudios públicos que tenía Ia Junta Preparatoria para el establecimiento de la actual Academia de San Fernando, en los que, ayudado de su buena dirección, hizo tales progresos que obtuvo el primer premio de la primera clase el año de 1753 en que la citada Academia celebró su primer concurso. Con este estimulo dobló su aplicación, de manera que fue declarado Académico de Mérito en 1758 por un baxorelieve de la Fragua de Vulcano que presentó a aquel cuerpo, cuios Directores celebraron mucho.

Desde este punto le trató su hermano no como a discípulo sino como a compañero, partiendo con él las utilidades de las obras; y para ser más estrecho el lazo de la buena harmonía, se caso don Pedro con doña Bárbara Ballerna, sobrina de doña Rosa Ballerna, muger de don Roberto, los que no teniendo hijos cuidaron de los de su hermano como propios, viviendo todos juntos en una propia casa y familia hasta la muerte de don Roberto, acaecida en 31 de enero de 1786.

Desde el de 1784 es don Pedro Teniente Director de la citada Academia y, condecorado con este título, le nombró el Rey su Escultor de Cámara en 5 de febrero de 1786, cuyos empleos desempeña a satisfación de S.M. Su hija doña Dorotea mereció elogios por una academia que dibujó y la de San Fernando presentó al público el año de 1793.

Las obras de nuestro don Pedro manifiestan su mérito y quanto procuró seguir las huellas de su hermano. Desde su muerte hasta el año de 1792 siguió de orden de S.M. en la restauración de las estatuas y bustos de mármol, pórfido y bronce que estaban en Ios sótanos de Palacio y que Roberto había principiado en 1784.

En 1787 presentó al Príncipe, ahora nuestro Rey, cinco medallas đe marfil que conserva en su gabinete; y de su orden executó dos jarrones para una chiminea (sic: chimenea) en los que esculpió unos bacanales, ocho capiteles de pilastras, cinquenta y quatro modillones de orden corintio y veinte y dos estatuas de a tercia para el ramillete, todo en mármol. También hizo la Virgen, San Josef y el Niño en el pesebre, los Reyes Magos y seis caballos en madera para el Nacimiento de Palacio.

\footnotetext{
${ }^{25}$ Sobre esta última obra, en el documento no se especifica nada más. Pardo Canalís, E.: Op. cit., pp. 45-46.

${ }^{26}$ Ibidem, pp. 46-47. El autor señala, además, que este Crucifijo se logró salvar del incendio que sufrió el templo en 1936.

${ }^{27}$ Ibidem, p. 47.

${ }^{28}$ Ibidem, p. 49.

${ }^{29}$ Nicolau Castro, J.: Escultura toledana del siglo XVII, Instituto Provincial de Investigaciones y estudios toledanos, Toledo, 1991, pp. 123, 241-242. Según el autor, estas figuras se conservan, aunque viejas y descompuestas, en los almacenes de la catedral.

${ }^{30}$ BN, Mss. 21.455, hojas 106-107.
}

AEA, LXXVII, 2005,312 , pp. 397 a 412 
Las demás obras públicas que conocemos de su mano son las siguientes:

Palacio nuevo. Real Librería. La escultura de estuco.

Salón de la reyna. La de esta pieza.

EI Pardo. Casa del Príncipe. Un escudo de piedra blanca en el áttico de la fachada.

Aranjuez. Jardín del Príncipe. Dos grupos de plomo sobre la puerta de este Jardín.

La fuente de Diana en mármol.

Madrid. Parroquia de San Salvador. El busto de la Duquesa de Arcos en el sepulcro de su marido, y varios bronces.

Casa del Príncipe de la Paz. El escudo de armas sobre la puerta principal.

Azpeitia. Parroquia. La estatua de San Sebastián en mármol, de once pies de alto, en la fachada principal.»

En esta ocasión, la información contenida en las obras de Ossorio y del Conde de la Viñaza coincide en lo fundamental con la facilitada por Ceán, salvo en la mención, por parte de los primeros, de una estatua de Carlos III vestido a la romana y situada en el Palacio de Oriente. Asimismo, estos dos autores aportan datos sobre la trayectoria del escultor tras la publicación del Diccionario al mencionar el nombramiento de Michel como Director de Escultura en 1804 y su fallecimiento, ocurrido cinco años después. A su vez, Ceán recoge algunas noticias en relación con la vida y producción del artista no citadas por los anteriores, como las referidas a su matrimonio o a la participación en las obras decorativas de los palacios Real Nuevo y de El Pardo.

Es Pardo Canalís quien, basándose en la documentación conservada en la Academia de San Fernando -y a la que, parece, ni Ossorio ni el Conde de la Viñaza tuvieron acceso-, proporciona datos más concretos sobre el escultor francés ${ }^{31}$. Siguiendo un escrito elaborado en 1831 por un tal Antonio Siles, este autor dice que Michel llega a Madrid el 19 de junio de 1748, señalando que dicha noticia no había sido precisada por el artista en ninguno de los restantes documentos consultados ${ }^{32}$, sin embargo, vemos cómo más de treinta años antes de la redacción del texto de Siles, el propio Ceán aporta idéntica información que, quizás, pudo obtener directamente del escultor.

En relación a los Premios Generales conseguidos por Michel, Pardo Canalís facilita el tema de la primera clase de escultura en la que el artista obtuvo el primer puesto: «El desembarco de Colón en Indias, quando fixó la Cruz». Sobre el relieve de la Fragua de Vulcano por el cual, según Ceán, fue nombrado Académico de Mérito, añade el anterior que estaba dorado de purpurina y que en 1789 hizo otro similar en madera para el despacho del Rey ${ }^{33}$.

Dentro de su actividad como Escultor de Cámara, será uno de los encargados de realizar el inventario de pinturas y esculturas legadas por Carlos III antes de su muerte, acaecida el 14 de diciembre de 1788.

De las obras que tras el fallecimiento de su hermano Roberto ha de restaurar -dice Pardo Canalís que en 1789 continuaba con esta labor, concretando Ceán su finalización en 1792- cita el primero «cuatro virtudes cardinales, ocho leones y dos escudos» y afirma que por entonces también tenía en su poder otras tantas, entre ellas el modelo de bronce dorado de la Fuente de los Cuatro Ríos, proyectada por Bernini en $1747^{34}$.

Por otra parte, no hay diferencias notables entre la producción de Michel citada por Ceán y la referida por Pardo Canalís pues parece que ambos se basan en un memorial redactado por el escultor en $1797^{35}$. Ceán recoge expresiones similares a las contenidas en este documento

\footnotetext{
31 Pardo Canalís, E.: Op. cit., pp. 10-15.

${ }^{32}$ Ibidem, p. 15.

${ }^{33} \mathrm{Ibidem}$. Este último relieve sería valorado por Francisco Sabatini en 3.000 reales. Es citado también por Plaza Santiago, F.J.: Investigaciones sobre el Palacio Real Nuevo de Madrid, Universidad de Valladolid, Valladolid, 1975, p. 266.

${ }^{34}$ Ibidem, p. 13.

${ }^{35}$ Ibidem, pp. 150-151. El documento en cuestión es el memorial de Pedro Michel en que solicita el puesto de Director de Escultura que desempeñaba Manuel Álvarez y que se fecha en Madrid el 31de marzo de 1797.
} 
y menciona las mismas obras, no encontrándose tampoco en él alusión alguna a la estatua de Carlos III del Palacio de Oriente, lo que evidencia que, efectivamente, fue la fuente utilizada en la elaboración del artículo ${ }^{36}$.

Sobre los grupos de figuras realizados en Aranjuez, Pardo Canalís matiza, apoyándose en la obra de Juan A. Álvarez de Quindós, que representan «unos geniecillos abrazados a un tiesto de flores, vaciado todo en plomo barnizado de blanco con mucha delicadeza y gusto» ${ }^{37}$. En relación a la obra ejecutada en este mismo lugar, Portela Sandoval facilita una descripción detallada de toda la ornamentación que el escultor haría junto a șu hermano para la Capilla del Real Palacio, lo cual no es citado por Ceán ${ }^{38}$.

Según Tárraga Baldó, también trabajarían los dos juntos en la decoración en estuco de la Pieza de Comer del palacio de El Pardo, siendo imposible identificar la parte realizada por cada uno dado el carácter unitario que presenta el conjunto ${ }^{39}$. Para Pardo Canalís, aparte del escudo ya mencionado por Ceán, podría ser obra de Pedro Michel la figurita de la fuente del patio de la misma residencia ${ }^{40}$.

Del Nacimiento ejecutado para Palacio, dice este mismo autor que se abonaron al escultor 9.400 reales en 1787 , sin embargo, en el documento en el que se basa no se refiere qué figuras realizó, al contrario que Ceán, que cita una serie de imágenes concretas para este encargo. Finalmente, alude a una estatua ecuestre de Carlos IV en «madera dorada de blanco», probablemente desconocida, que aparecería mencionada en un catálogo manuscrito de las esculturas de la Academia de San Fernando y que no ha sido nombrada hasta el momento en ningún otro texto ${ }^{41}$.

\section{«Rodríguez Díaz (D. Josef) escultor ${ }^{42}$}

Conocido con el mote de Sócrates que, segán dicen, le puso su maestro don Felipe de Castro. Nació en el lugar de San Pedro de Segerey del obispado de Lugo el año de 1746. Pasó a Madrid a los catorce años de edad a aprender la escultura y su paysano Castro le recibió por su discípulo. En el de 1769, con su aplicación obtuvo el primer premio de la segunda clase en la Real Academia de San Fernando, en 1781 el segundo de la primera y 1785 fue recibido por Académico de Mérito.

Son muchas las obras públicas y privadas que le proporcionó su crédito dentro y fuera de la Corte. Entre las que hizo para particulares se cuentan los bustos en mármol del tamaño del natural de los Excelentísimos Señores Duque de Liria, Duque de Aliaga y Duque de Hijar, Conde de Campomanes, Conde de Lerena, Conde de Floridablanca y de don Josef de Silva. Trabaxó también los modelos de la escultura o adornos que ha-

\footnotetext{
${ }^{36}$ A tenor de la mencionada escultura de Carlos III, añade Pardo Canalís su falta de esbeltez y su excesiva anchura. Ibidem, p. 14. Por el contrario, Umrea, J.: Op. cit., p. 120, la considera «su obra más monumental e interesante, por lo que supone de decidida aceptación de cánones clásicos».

${ }^{37}$ Álvarez de Quindós y Baena, J. A.: Descripción histórica del Real Bosque y Casa de Aranjuez, Madrid, 1804, p. 298; Pardo Canalís, E.: Op. cit., p. 27.

${ }^{38}$ Portela Sandoval, F.J.: «La ornamentación escultórica en la arquitectura de Sabatini» en Francisco Sabatini, 1721 1797, Real Academia de Bellas Artes de San Fernando, Madrid - Centro Cultural Isabel de Farnesio, Aranjuez, octubre diciembre, 1993, pp. 192-193. Esta colaboración de los Michel es mencionada asimismo por Tovar Martín, V.: «La Capi1la Real de Aranjuez. La 'distinción' de un espacio 'oculto' al exterior», Reales Sitios, Madrid, año XXX, n. ${ }^{\circ} 117,3$. ${ }^{\circ}$ trimestre, 1993 , pp. 45-54.

39 Tárraga Baldó, $\mathrm{M}^{\mathrm{a}}$.L.: «Los estucos de Roberto Michel para el palacio de El Pardo», A.E.A., Madrid, $\mathrm{n}^{\circ} 247,1989$, pp. 323-326; Sancho, J.L.: «Las decoraciones fijas de los palacios reales de Madrid y El Pardo bajo Carlos Ill» en El Arte en tiempo de Carlos III, IV Jornadas de Arte del Instituto Diego Velázquez, C.S.I.C., Madrid, 1989, p. 227, considera esta sala la más suntuosa del conjunto. Asimismo, señala este autor que Pedro Michel aparecería también relacionado con el ornato del oratorio del Palacio Real de Madrid al actuar como apoderado de su hermano, recibiendo, a finales de 1767, ciertas cantidades a tenor «del importe del adorno de la mesa de altar, grada y cuatro sobrepuertas que ejecutó para el oratorio de S.M.».

${ }^{40}$ Pardo Canalís, E.: Op. cit., p. 14.

${ }^{41}$ Ibidem. El autor señala que en el mismo manuscrito se indica que dicha imagen estaba situada en la biblioteca antigua.

${ }^{42} \mathrm{BN}$, Mss. 21.455, hoja 136.

$A E A$, LXXVIU, 2005,312 , pp. 397 a 412
} 
brá de llevar el nuevo templo de Covadonga, los quales existen en la Real Academia de San Pernando.

Las públicas que conocemos son estas:

Madrid. Santo Thomas. EI Sepulcro del Excelentísimo Señor Conde de Gausa en la capilla de Nuestra Señora del Rosario.

San Martín. El del Excelentísimo Señor don Manuel Ventura de Figueroa en la de Valbanera.

Paseo del Prado. Diez y seis cabezas de oso para las quatro fuentes menores.

Escuela pía de Abapies. La estatua de Santa Bárbara en su altar.

San Pedro. Dos ángeles en el altar mayor.

Ávila. Catedral. La medalla, estatuas y adorno de la puerta principal.

Burdongo (sic: Busdongo, Burgohondo). Parroquia. Una Virgen de los Dolores.

Escorial. Casino del Infante don Gabriel. Una fuente con su adomo y reedificó otra.

Natabalgordo (sic: Navatalgordo). Parroquia. La estatua de San Miguel.

Chinchón. Parroquia. Una Concepción.

Villaconejos. Parroquia. La estatua de Santa Ana.

Móstoles. Parroquia. La del Beato Simón de Roxas.

Colmenar de Oreja. Parroquia. Otra de este mismo santo.

Tuy. Catedral. La de San Telmo.

Una Virgen de los Dolores.»

Es singular el caso de este artista al que Ceán califica como escultor reconocido dentro y fuera de la Corte cuando, en cambio, Ossorio sólo le dedica unas líneas ${ }^{43}$ mientras que el Conde de la Viñaza ni siquiera le incluye en sus Adiciones y, del mismo modo, tampoco es nombrado por el resto de estudiosos anteriormente citados en relación a los demás escultores ${ }^{44}$.

Habrá que esperar al año 2002 para encontrar un artículo centrado en la actividad del artífice ${ }^{45}$. Sin embargo, la autora del mismo se basa casi con exclusividad en la documentación conservada en la Real Academia de San Fernando y no refiere un número importante de obras realizadas por Rodríguez Díaz fuera del ámbito académico ${ }^{46}$. No obstante, se mencionan en él una serie de datos no recogidos por Ceán, entre ellos, el tema de los relieves premiados en los concursos de la Academia ${ }^{47}$ y el presentado tras su recepción como Académico de Mérito ${ }^{48}$, así como la participación del escultor en la reforma del Colegio Imperial en 1769, la ejecución de una cabeza y unas manos para un Santo Tomás encargado en 1778 por un particular, la intervención junto con José Guerra y Pablo de la Cerda en la finalización de la carroza de la fuente de Neptuno o la realización de un proyecto para un segundo cuerpo de madera en el trascoro de la catedral de Ávila que finalmente no se llevaría a cabo ${ }^{49}$.

Entre los años de 1785 y 1791, Rodríguez Díaz desarrollaría su etapa más fructífera al contar con la protección de Pedro Rodríguez de Campomanes, presidente del Consejo de Castilla. Será entonces cuando ejecute los bustos de varios personajes destacados de la época, como el del propio Campomanes, el del Conde de Floridablanca, primer ministro, el de Ventu-

\footnotetext{
${ }^{43}$ Este autor únicamente cita como obras de Rodríguez Díaz una copia del Ganímedes y los bustos del Conde de Campomanes y de D. Ventura de Figueroa, conservadas en la Real Academia de Bellas Artes de San Fernando. Ossorio y Bernard, M.: Op. cit., p. 589.

${ }^{44}$ Sólo Martín González, J.J.: «Los escultores...», Op. cit., p. 261, incluye una breve referencia a los premios conseguidos por el artista en la Academia de San Fernando, facilitando el tema del obtenido en 1781: «Alegoría del Nacimiento del Príncipe Heredero».

${ }^{45}$ Cruz Yábar, M.`T.: «El escultor José Rodríguez Díaz, "Sócrates" (h. 1746 -1817)», Espacio, Tiempo y Forma, Serie VII, $\mathrm{H}^{\mathrm{a}}$. del Arte, Madrid, t. 15, 2002, pp. 169-188.

${ }^{46}$ Así sucede con las obras citadas por Ceán en Ávila, Busdongo, El Escorial, Navatalgordo, Chinchón, Villaconejos. Móstoles, Colmenar de Oreja y Tuy.

${ }^{47}$ En 1769 , año en que Rodríguez Díaz obtuvo el primer premio de la segunda clase, el relieve representaba el tema «Fernando I arma caballero al Cid», y en 1781, en que obtiene el segundo premio de la primera clase, mostraba una «Alegoría del nacimiento del infante Carlos Eusebio», tema ya citađo por J.J. Martín González (ver nota 44). Ambos se conservan en la Real Academia de Bellas Artes de San Fernando. Cruz Yábar, Ma.T.: Op. cit., pp. 176-181.

${ }^{48} \mathrm{Ibidem}$, p. 171. Se trataba del relieve del Martirio de San Esteban. Una mención a esta obra se encuentra en Azcúe Brea, L.: Op. cit., p. 295.

${ }^{49}$ Cruz Yábar, M. ${ }^{\mathrm{a} T}$.: Op. cit., pp. 171-172.
} 
ra Figueroa, anterior presidente del Consejo o el de Miguel Múzquiz, Conde de Gausa y ministro de Hacienda ${ }^{50}$. Ceán menciona los mismos a excepción de los dos últimos -seguidamente indicaremos por qué-, e incluye, además, los retratos de los Duques de Liria, de Aliaga, de Híjar, del Conde de Lerena y de José de Silva.

Según parece, el único que se conserva en su versión definitiva es el del Conde de Floridablanca, actualmente en el Museo del Prado, y que, hasta hace poco tiempo, se creía representaba al arquitecto Juan de Villanueva. Tampoco se sabía quién lo había realizado a pesar de tener grabado el apellido del escultor, siendo Cruz Yábar quien lo atribuye a José Rodríguez Díaz ${ }^{51}$. El documento de Ceán es fundamental para apoyar esta atribución a la vez que abre nuevas vías de investigación al dar a conocer una serie de obras de las que, hasta el momento, no se tenía constancia.

Los modelos en yeso de los retratos de Ventura Figueroa y de Miguel de Múzquiz se guardan en la Academia de San Fernando. Del primero dice Cruz Yábar estar «dentro de lo posible que el busto fuera el modelo del que se colocó én el sepulcro del eclesiástico en la iglesia de San Martín» ${ }^{52}$, obra también mencionada por Ceán. Según la misma autora, el de Miguel de Múzquiz, Conde de Gausa, pudo estar destinado igualmente a su sepulcro, aunque afirma no saber nada de su situación y características ${ }^{53}$, cuestión resuelta en el artículo redactado por el anterior, que emplaza dicho enterramiento en la capilla de Nuestra Señora del Rosario de la iglesia de Santo Tomás de Madrid. Por otra parte, ya hemos aludido a que el autor del Diccionario no incluye en su relación los retratos de estos dos personajes de los que, en cambio, sí se conserva su modelo en yeso, lo cual podría responder al hecho de que no estaban concebidos como bustos exentos - como podría ser el de Floridablanca- sino como parte de los conjuntos sepulcrales referidos en el documento ${ }^{54}$. Del modelo en yeso del retrato del Conde de Campomanes opina Cruz Yábar que sería el utilizado para realizar el busto en mármol que poseía el Duque de Valencia en $1902^{55}$.

Durante este mismo período, recibiría Rodríguez Díaz el encargo de las esculturas del nuevo templo de Covadonga proyectado por Ventura Rodríguez. Debía ejecutar el escultor las imágenes de Pelayo y Favila para unos nichos en el pórtico de la segunda planta del edificio, dos leones que adornarían el arranque de la escalinata y dos trofeos de cuatro caras destinados al final de la balaustrada del monumento, sin embargo, la obra finalmente no se llevó a cabo, quedando los modelos de Rodríguez Díaz depositados en la Academia de San Fernando, tal como alude Ceán y donde aún permanecían en 1804, estando ahora desaparecidos ${ }^{56}$.

Señala además Cruz Yábar que la existencia de otro escultor contemporáneo a Rodríguez Díaz y llamado José Rodríguez puede haber provocado en algún momento la confusión entre la trayectoria de ambos. Así sucedería con la Santa Bárbara para las Escuelas Pías de San Fernando que cita Ceán en relación con Rodríguez Díaz ${ }^{57}$ y que, en cambio, esta autora menciona como posible obra de José Rodríguez ${ }^{58}$.

\footnotetext{
${ }^{50}$ Ibidem, pp. 172-173.

s] Ibidem, pp. 186-188.

52 lbidem, p. 183.

Thidem, p. 186 .

${ }^{54}$ Ibidem, p. 183. A este respecto, señala M. ${ }^{a}$ Teresa Cruz que era costumbre entre los académicos el mostrar a sus compañeros las obras destacadas que realizaban para sitios públicos y que, en el caso de los escultores, era habitual que depositasen en la Academia los modelos que habian utilizado para llevarlas a cabo.

${ }^{55}$ Ibidem, p. 173. Este modelo, actualmente desaparecido, se conservó también en la Real Academia de Bellas Artes de San Fernando.

${ }^{56}$ Ibidem, pp. 173-175. Estas realizaciones le serían abonadas tras una larga polémica.

${ }^{57}$ Tormo, E.: Las iglesias del Antiguo Madrid, Instituto de España, edición de Madrid, 1979, p. 56, también atribuye esta imagen a José Rodríguez «Sócrates» aunque añade que se trata de un escultor al que no se conoce más que por esta obra.

${ }^{58}$ Cruz Yábar, M.*T.: Op. cit., p. 188. Parece ser de este José Rodríguez el Ganímedes que Ossorio atribuía a Rodríguez Díaz y que, en cambio, Ceán no incluye en el documenta que damos a conocer.
}

AEA, LXXVIII, 2005, 312, pp. 397 a 412 
A finales de 1797, después de habérsele denegado varios puestos en la Academia, consigue el cargo de maestro mayor de escultura en el Arsenal de la Carraca en Cádiz, empleo que detenta hasta 1803 en que es despedido por incompatibilidad de pareceres con el Ministerio de Marina pero que recupera posteriormente en 1805. Rodríguez Díaz permanecería en esta ciudad hasta su fallecimiento, ocurrido el 21 de septiembre de 1817, sin embargo, nada se sabe hasta el momento de la obra que pudo ejecutar allí ${ }^{59}$.

\section{«Rudiez (D. Vicente) pintor y escultor ${ }^{60}$}

[Encima del título: 'Vive'].

Nació en la ciudad de Cascante, en Navarra, el año de 1740. Principió a delinear arquitectura en Zaragoza a los once de edad y en el de 1752 pasó a Roma y se dedicó a la escultura baxo la enseñanza de Felipe de la Valle, asistiendo al mismo tiempo a la Academia de San Lucas, en la que obtuvo el premio de la segunda clase el año de 1755 y en el siguiente el de la primera. También se ocupó en la pintura haciendo muchas vistas y ruinas de aquella capital para los ingleses y de escultura un apostolado de mármol de Carrara.

Volvió a Madrid en 1759 y la Real Academia de San Fernando le señaló una pensión anual de ciento y cinquenta ducados.

Don Antonio Rafael Mengs le encargó una copia del tamaño de uná vara en escultura de la celebre Cleopatra que está en el real palacio de San IIdefonso, que por haber salido a su gusto la llevó a Roma.

En 1788 la citada Academia de San Fernando le recibió en el número de sus individuos de Mérito en esta última facultad, y vive en Madrid exerciendo las dos con buen crêdito, cuyas obras públicas son las siguientes:

Madrid. La Victoria. Las estatuas de los beatos Bono y Longobardo en la iglesia.

Capuchinos del Prado. La de San Miguel de Simiringa (sic: Sigmaringa) en el altar mayor.

San Ginés. Las de los quatro Doctores, la de la Fe, unos ángeles y quatro baxos relieves que están en el tabernáculo del altar mayor.

San Francisco. El lienzo de Nuestra Señora de la Concepción en ademán de proteger la religión seráfica, colocado sobre los caxones de la sacristía.

Olite. Convento de San Francisco. Una copia de una Concepción de Carlos Marata y una Santa Margarita de Cortota (sic: Cortona). Ambos los pintó en Roma.

Rueda. Capuchinos. La estatua del Beato Brindis en la iglesia.

Alberca en la Mancha. Convento de Carmelitas. Las de San Elías y de San Marcos en la iglesia.

El Pardo. Real Capilla. Otra de Nuestra Señora del Rosario.

Ciudadrodrigo (sic: Ciudad Rodrígo). Padres Mostenses. Dos quadros grandes en el altar mayor que representan la Visitación a Santa Isabel y el Nacimiento del hijo de Dios.»

Rudiez, dedicado igualmente a la pintura y a la escultura, es incluido en este artículo junto con los escultores por ser mayor el número de obras suyas citadas por Ceán correspondientes a esta disciplina. Frente a Ossorio y el Conde de la Viñaza, que se basan de nuevo en la información contenida en las actas de la Academia de San Fernando, es el autor del Diccionario quien da a conocer un mayor número de datos sobre este artista. Es el único que aporta la fecha y el lugar de nacimiento de Rudiez, así como las noticias relativas a su formación antes del ingreso en la Academia, de donde fue nombrado individuo de Mérito en 1788. Según los otros dos autores, este nombramiento se produciría en 1778, aunque la fecha correcta parece ser la facilitada por Ceán pues coincide con el listado de Académicos realizado por el personal del Archivo de la Real Academia de Bellas Artes de San Fernando y con el que figura en el catálogo de Azcúe ${ }^{61}$. En relación a su etapa de pensionado en Roma, Ceán sitúa la vuelta del escultor en 1759 mientras que Martín González afirma que en 1763 Rudiez todavía permanecía en aquella ciudad ${ }^{62}$. En cambio, sólo Ossorio y el Conde de la Viñaza mencionan el falle-

\footnotetext{
${ }^{59}$ Ibidem, pp. 175-176.

${ }^{60} \mathrm{BN}, \mathrm{Mss} .21 .455$, hojas 146-147.

${ }^{61}$ Azcúe Brea, L.: Op. cit., p. 7.

${ }^{62}$ Martín González, J.J.: «Los escultores...», Op. cit., p. 261.
} 
cimiento del artista, ocurrido el 25 de octubre de 1802. Por otra parte, estos dos autores únicamente citan como obras suyas - y dicen ser las nombradas en la necrológica inserta en las actas de la Academia - «las estatuas que trabajó para el adorno de la fachada del palacio de los Duques de Medinaceli y otras varias de santos para la iglesia de Padres Mínimos de la Corte» 63 .

Serrano Fatigati alude a la producción del escultor en Madrid, observándose diferencias con los datos proporcionados por Ceán, ya que el primero señala que en los capuchinos del Prado lo que ejecutó Rudiez fue la imagen de San Fidel y no de San Miguel, como dice el anterior. Además, añade una Virgen del Pilar para el Conde de Atarés y las imágenes de $L a$ Música y El Baile para el corral de la Cruz ${ }^{64}$. Cavestany le atribuye, aparte del San Fidel mencionado, un Resucitado que remataba el tabernáculo del mismo templo ${ }^{65}$.

Estella Marcos comenta la posibilidad de que fuese asimismo de Rudiez la imagen de la Divina Pastora que se encuentra en la iglesia de Jesús de Medinaceli ${ }^{66}$. No obstante, la falta de información al respecto impide ir más allá de éstas suposiciones a la vez que muestra la necesidad de un análisis en profundidad de la obra de este artífice.

\section{«San Martín (D. Julián de) escultor ${ }^{67}$}

El talento, el estudio y la aplicación suplen algunas veces en las bellas artes la buena dirección del maestro que no pudo lograr este profesor. Nació en la villa de Valdelacuesta, merindad de Cuentaurria (sic: Cuestaurría), en el arzobispado de Burgos. Sus parientes le enseñaron algunos principios de su facultad en proporción de los que ellos habían adquirido sin salir del pays. No pensó así don Julián, que a los diez y siete año (sic: años) de edad pasó a Madrid con el fin de aventajarlos y de aspirar a la perfección. Para cimentarse en el dibuxo asistió con tesón a la Academia de San Fernando y se dio tan buena traza que a los dos años obtuvo el primer premio de la segunda clase en el de 1781 y en el concurso general siguiente de 1784 el primero de la primera, y esto sin protección ni otro maestro que don Vicente Ruidiez (sic: Rudiez) que le dio algunas lecciones.

Tan rápiđos progresos (tachado: hicieron) fueron admirados de los directores y demás individuos de la Academia, los que le proporcionaron obras para lucir su mérito. Don Antonio Ponz le encargó la estatua de San Martín, obispo de León. Otra don Mariano Maella. Por influxo de don Ventura Rodríguez executó la de la Beata Mariana de Jesús para las fiestas de su beatificación en la parroquia de Santiago de Madrid y el viceprotector Marqués de la Florida le recomendó al Director don Manuel Álvarez quando volvió de Toledo para que le dirigiese $y$, en efecto, le corrigió sus obras.

Fue recibido Académico de Mérito en dicho cuerpo el año de 1786 y Teniente de Director en 30 de abril de 1797 y sigue trabajando en Madrid con reputación. Diremos las obras públicas que ha hecho y que conocemos:

Huerta. Monasterio de Bernardos. La citada estatua de San Martín, obispo de León y monge de esta orden. Madrid. Parroquia de Santiago. La referida de la Beata Mariana.

Santo Domingo el Real. La de Santa Anastasia.

San Francisco. La de San Francisco en la capilla de la Tercera Orden.

Hospital de la $3^{a}$ Orden. Toda la escultura del altar mayor, menos la Concepción.

San Sebastián. Los Evangelistas del tabernáculo y los ángeles del altar mayor.

Las estatuas de la huida a Egypto por modelo de don Manuel Álvarez.

San Justo y Pastor. La de la Virgen de la Cabeza.

Capilla de la Soledad en la calle de la Paloma. La escultura de su retablo.

Escuela pía de Avapies. Las estatuas del Ángel de la Guarda y de Santa Casilda.

\footnotetext{
${ }^{63}$ Ossorio y Bernard, M.: Op. cit., p. 602; Viñaza, conde de la: Op. cit., p. 327.

${ }^{64}$ Serrano Fatigati, E.: Op. cit., p. 187.

${ }^{65}$ Cavestany, J.: «La Anunciación (cuadro inédito de Goya)», Arte Español, Madrid, tomo IX, 1928-1929, p. 352. El autor afirma que el artista sería protegido de los Duques de Medinaceli y que realizaría otras estatuas para el palacio de éstos, lo que coincide con lo citado por Ossorio y el Conde de la Viñaza.

${ }^{66}$ Estella Marcos, M.: «Miscelánea de Escultura del siglo xvin» en El Arte en tiempo de Carlos III, IV Jornadas de Arte del Instituto Diego Velázquez, C.S.I.C., Madrid, 1989, pp. 249-250.

${ }^{67}$ BN, Mss. 21.455, hojas 177-178.
}

AEA, LXXVILI, 2005, 312, pp. 397 a 412 
Nuevas Salesas. La medalla de la fachada.

Santo Domingo de la Calzada.- Catedral. La del santo titular sobre su sepulcro.

Segovia. Catedral. Las estatuas de la Concepción y de San Josef.

Meco. Parroquia. Un Santo Christo y una Dolorosa.

Arjona. Iglesia de San Juan. Otra de San Josef.

Albuquerque. Parroquia. Otra del mismo santo patriarca.

Medina del Campo. Colegiata. Las de San Rafael y de San Josef.

Leganés. Hermita de San Nicasio. La de San Vicente.»

Las noticias más representativas en relación con este escultor son las proporcionadas, primero, por Ossorio y por el Conde de la Viñaza, ya que, aún sin mencionar algunas de las realizaciones que registra Ceán en su escrito, concuerdan con éste en la mayor parte de los datos que refieren ${ }^{68} \mathrm{y}$, además, aportan otra serie de ellos que no son citados por el anterior ${ }^{69}$.

Con posterioridad, es Tárraga Baldó quien facilita información más detallada al dar a conocer un memorial redactado por el propio San Martín en $1797^{70}$. Se trata de un documento de gran importancia pues no sólo incluye las obras consignadas por Ossorio y el Conde de la Viñaza, así como algunas anotadas únicamente por Ceán, sino que además recoge otras de las que hasta el momento no se tenía constancia. El texto de éste último coincide con dicho memorial al mencionar los trabajos del artista en la Corte, registrándose las realizaciones para Santo Domingo el Real, para el Hospital de la Tercera Orden, las de la iglesia de San Sebastián y las de la Capilla de la Soledad que no se incluían en las relaciones de Ossorio y el Conde de la Viñaza. Las que éstos aportaban, recogidas asimismo por Tárraga, y que, en cambio, no figuran en el artículo de Ceán, eran un bajorrelieve de Esaú y Jacob conservado en la Academia de San Fernando ${ }^{71}$, otro que representaba la Asunción y Dos Mancebos para la Catedral de Pamplona, una Asunción en Medina del Campo y un modelo para la estatua ecuestre de Felipe V. En el memorial de San Martín solamente se cita para la parroquia de Santiago la imagen de la Beata Mariana de Jesús, lo que concuerda con el escrito de Ceán, siendo probable que no pertenezca al artista la Santa Teresa conservada en el mismo lugar que le atribuyen Ossorio y el Conde de la Viñaza. Igualmente, consideran éstos una Santa Cecilia la que Ceán denomina Santa Casilda, situada en las Escuelas Pías de San Fernando ${ }^{72}$.

\footnotetext{
${ }^{68}$ Difieren, sin embargo, en la fecha del nombramiento de San Martín como Teniente Director de Escultura de la Academia, situado en 13 de abril por los dos últimos autores. Ossorio y Bernard, M.: Op. cit., p. 628; Viñaza, conde de la: $O p$. cit., p. 352 .

${ }^{69}$ No podemos saber por qué Ceán no alude a algunas de las obras que los otros dos autores mencionan, y viceversa, ya que San Martín fállece en 1801 y, con toda probabilidad, habría ejecutado prácticamente toda su labor artística antes de la publicación del Diccionario. Es posible que Ceán, contemporáneo del artista, conociese la existencia de estas realizaciones a través del mismo -como sucede en otros casos-y que, posteriormente, Ossorio y el Conde de la Viñaza no las incluyesen por falta de documentación en relación a las mismas.

${ }^{70}$ Tárraga Baldó, M.²L.: «España y América en la escultura cortesana de la segunda mitad del siglo XVIII: corrientes recíprocas de influencia» en Relaciones artísticas entre España y América, Instituto Diego Velázquez, CSIC, Madrid, 1990, pp. 248-253. Los estudios de Serrano Fatigati no aportan nada nuevo pues, al igual que Ossorio y el Conde de la Viñaza, se apoya básicamente en la documentación conservada en la Academia de San Fernando. Serrano Fatigati, E.: Op. cit., pp. 152-153. Coincidiendo con los datos referidos por Ceán, Portela Sandoval, F.J.: «Noticias sobre algunos artistas que estudiaron en la Real Academia de Bellas Artes de San Fernando en tiempos de Carlos III", El Arte en tiempo de Carlos MI, IV Jornadas de Arte del Instituto Diego Velázquez, C.S.I.C., Madrid, 1989, p. 455, indica el momento de ingreso del artista en la citada Academia, ocurrido el 22 de mayo de 1779. Azcúe Breá, L.: Op. cit., p. 292, señala fa realización de un relieve con el tema del Martirio de San Esteban, gracias al cual San Martín conseguiría el nombramiento de Académico de Mérito. Asimismo, afirma esta autora que en 1778 el artista había sido nombrado Maestro Mayor de Escultura en el Arsenal de Carraca de Cádiz, dato susceptible de ser analizado más detenidamente puesto que se habría producido antes del ingreso del artista en la propia Academia de San Fernando, hecho que parece bastante improbable.

${ }^{71}$ Es uno de los motivos propuestos para el concurso de 1781 en el cual obtuvo San Martín, como indica Ceán en el documento, el primer premio de la segunda clase. Azcúe Brea, L.: Op. cit., pp. $291-292$.

${ }^{72}$ Indican también estos autores que el prestigio de que gozaba el escultor pudo depender, según las actas de la Academia de San Fernando, «de su celeridad en el trabajo, equiđad en los precios, exactitud en sus tratos y regularidad en sus costumbres». Ossorio y Bernard, M.: Op. cit., p. 628-629; Viñaza, conde de la: Op. cit., p. 352.
} 
Asimismo, en el documento dado a conocer por Tárraga se mencionan otra serie de obras del escultor en la Corte a las que no alude Ceán, como las medallas ejecutadas para el interior de las Salesas, una Santa Cristina para los padres Bernardos, las medallas y estatuas en estuco y escayola para distintas salas del Palacio Real, varias figuras para el Nacimiento del Infante Don Gabriel que después se situarían en el de Palacio, un retrato de Carlos IV y un caballo para que el futuro Fernando VII, todavía Príncipe, llevase a cabo sus primeros ensayos de montar. En relación a la producción del artista fuera de este ámbito cortesano, y no citada anteriormente por ninguno de los autores mencionados, se encuentra la imagen de San Juan Evangelista que se conserva en la iglesia de San Nicolás de Medina, actual San Esteban, de Huete (Cuenca). Destaca especialmente dicha autora los distintos encargos realizados a San Martín con destino a América. Ossorio se había hecho eco ya de unas esculturas de San Antonio y San Francisco para la Habana ${ }^{73}$, aclarando Tárraga que estas imágenes serían ejecutadas para el Colegio de Capuchinos de dicha ciudad y que serían costeadas por Carlos IV. Junto a éstas, refiere otras de los mismos santos para los franciscanos de Chile y una Virgen para Buenos Aires ${ }^{74}$.

Con todo, siguen sin aparecer citadas las que Ceán sitúa en Huerta, Meco, Arjona, la Colegiata de Medina del Campo y Leganés.

Más adelante, Nicolau Castro publica otro breve memorial que el escultor habría elaborado en julio de 1789 para solicitar que se le encomendasen alguna de las obras proyectadas en la fachada de las Salesas Reales ${ }^{75}$. Este escrito, unos años anterior al presentado por Tárraga, contribuye a fechar la intervención de San Martín en dicho edificio y a discutir su papel en las realizaciones para la iglesia del Hospital de la Venerable Orden Tercera ${ }^{76}$. En el artículo de Ceán se indica claramente que el artista habría ejecutado para este lugar toda la escultura del retablo mayor a excepción de la Inmaculada. Asimismo, en el memorial localizado por Tárraga, el escultor sólo menciona para el mismo templo las de San Francisco y San Antonio y los ángeles y medallas del altar mayor ${ }^{77}$. Sin embargo, en el documento facilitado por Nicolau, San Martín afirma haber realizado «toda la escultura del retablo» ${ }^{78}$, entendiendo que también sería de su mano la de la Inmaculada.

Este memorial de 1789 , además de invitar a la revisión de importantes cuestiones en torno a la producción de San Martín, es interesante también porque alude a una obra del artista no citada previamente: los ángeles del retablo mayor de la parroquia de San Miguel. De igual

\footnotetext{
${ }^{73}$ Según este autor, fueron las estatuas que mayor renombre le proporcionaron. Ossorio y Bernard, M.: Op. cit., p. 629 .

${ }^{74}$ Tárraga Balđó, M. ${ }^{\mathrm{L} L .:}$ «España y América...», Op. cit., p. 251. Comenta la autora no tener noticia alguna sobre el estado de conservación ni la fecha concreta đe ejecución de dichas obras. Aporta también en su estudio datos interesantes en relación a los orígenes del artista, como el año de nacimiento - 16 de febrero de $1762-0$ sus pretensiones para conseguir el nombramiento de escultor de Cámara; señala asimismo la posibilidad de que el escultor estuviese relacionado a través de vínculos maternos con los artistas Pascual, Pedro y Ángel Monasterio, gracias al cual el artista se habría decidido a viajar a la Corte. Siguiendo a Ceán, San Martín recibiria su primera formación de la mano de ciertos parientes que se suponen artistas pero que no habrían salido de la provincia. Sobre los premios conseguidos por el escultor en la Academia, Ceán, Ossorio y el Conde de la Viñaza afirman ser uno en 1781 y otro en 1784, que coincidirían con los que Tárraga registra en 1782 y 1785 pues, recordemos que, a pesar de que la convocatoria de los Premios Generales se produce en ún año, la entrega de los mismos se efectúa a principios del siguiente.

${ }^{75}$ Nicolau Castro, J.: «Las esculturas del retablo mayor de la Capilla de la Enfermería de la V.O.T. de Madrid», A.E.A., Madrid, tomo LXXII, n 26, abril-junio, 1999, pp. 133-144.

${ }^{76}$ Indica el autor que tradicionalmente se han venido confundiendo las imágenes realizadas para este lugar con las dispuestas en la Capilla del Cristo de los Dolores, también de la V.O.T. Nicolau Castro, J.: «Las esculturas...», Op. cit., p. 140.

${ }_{77}$ Tárraga Baldó, M. ${ }^{\mathrm{L}}$.: «España y América...», Op. cit., p. 250.

${ }^{78}$ Se trata de las imágenes de San Francisco de Asís, de San Antonio de Padua, dos medallones con las efigies de San Pedro y San Pablo, así como los ángeles y ángeles mancebos que completan el conjunto. Nicolau Castro, J.: «Las esculturas...», Op. cit., p. 140.
}

$A E A$, LXXVIII, 2005, 312, pp. 397 a 412 
modo, recoge Nicolau en su artículo la existencia de una versión de la Beata Mariana de Jesús que se conserva en el Victoria \& Albert Museum de Londres ${ }^{79}$.

\section{«Sancho (D. Dionisio) escultor ${ }^{\$ 0}$}

(En la parte superior derecha de la hoja, tachado: 'Vean si' y detrás, 'Vive')

Nació en la villa de Cienpozuelos (sic: Ciempozuelos) el año de 1762 y en el de 1793 obtuvo el primer premio de la primera clase en la Real Academia de San Fernando. En 10 de enero de 1796 fue nombrado individuo de Mérito de este sabio cuerpo.

Aprendió los principios de su arte con don Francisco de la Fuente, arquitecto de su patria. Trasladado a Madrid en 1776 hizo rápidos progresos baxo la dirección de don Vicente Rudiez, trabaxando en varias obras públicas y privadas, especialmente en las fuentes del Prado.

Fue empleado por el Rey el año de 1788 en la plaza de modelante de la Real Fábrica de Porcelana en el Buen Retiro con sueldo decente y en el de 1795 le confirió S.M. los honores de su Escultor de Cámara.»

Sorprende, en este caso concreto, que Ceán no cite ninguna de las obras realizadas por el escultor en la Corte, pues, según la información facilitada por Ossorio y por el Conde de la Viñaza, no debió de ser un artista poco conocido ya que, tras recibir los nombramientos de Director del Adorno de la Fábrica de Porcelana del Buen Retiro y de Escultor de Cámara, fue designado Teniente Director Honorario de la Academia de San Fernando en 1805 y Director de Escultura de la Academia de Méjico en 1810, pasando tres años después a Ia de Guadalajara y Zacatecas ${ }^{81}$. No obstante, tampoco estos autores mencionan la producción americana del escultor, sino la ejecutada en la Corte y que Ceán pudo conocer igualmente pues parece realizada con anterioridad a la marcha de Sancho, si bien, algunas de las obras más destacadas debieron llevarse a cabo entre el periodo de publicación del Diccionario y la partida del escultor a Méjico ${ }^{82}$.

Las obras citadas por Ossorio y por el Conde de la Viñaza son una estatua colosal de $\mathrm{Mi}$ nerva situada en el jardín de la casa de Manuel Godoy, una Virgen de la Esperanza en la parroquia de San Justo, dos bajorrelieves de marfil para el Casino del Príncipe en El Escorial y otro, de la misma materia, en la galería de escultura del Museo del Prado. Ossorio señala además un Cristo, también de marfil, del que no dice su situación ${ }^{83}$, pero sólo Ceán se ocupa del periodo de formación del artista y menciona su participación en las fuentes del paseo del Prado, datos que no incluyen los anteriores.

Son las investigaciones llevadas a cabo por Tárraga Baldó las que proporcionan datos nuevos en relación con la vida y producción de este desconocido escultor ${ }^{84}$. Las primeras noticias documentales datan de 1788, en que Sancho, que por entonces contaba con veintiséis años, se

${ }^{79}$ Ibidem, p. 144. Esta escultura de terracota se encuentra catalogada en Trusted, M.: Spanish Sculpture. A catalogue of the collection in the Victoria \& Albert Museum, London, 1996, pp. 75-76.

${ }^{80}$ BN, Mss. 22.491, hoja 290.

${ }^{81}$ El escultor regresaría después a Méjico, donde falleció en 1829. Ossorio y Bernard, M.: Op. cit., p. 628-629; Viñaza, Conde de la: Op. cit., p. 352.

${ }^{82}$ Es curioso cómo Sancho, fallecido en el primer tercio del siglo XIX, tampoco es considerado con mayor detenimiento en los estudios de Serrano Fatigati y Pardo Canalís, pues, ya se ha comentado, parece ser un artista no carente de importancia y, sin embargo, estos autores solamente aluden a algún hecho aislado de su trayectoria, como la solicitud de la plaza de Escultor de Cámara el 25 de febrero de 1795 y que deja vacante en 1816, cuando el artista está ya en Méjico. Serrano Fatigati, E.: Op. cit., p. 188; Pardo Canalís, E.: Op. cit., p. 184.

${ }^{83}$ Ossorio y Bernard, M.: Op. cit., p. 629.

${ }^{84}$ Tárraga Baldó, M.L.: «España y América...», Op. cit., pp. 238-242. La autora, que afírma no conocer más noticias sobre Sancho que las que hemos mencionado ya en este artículo, da a conocer la documentación relacionada con el artista que se conserva en el Archivo General del Palacio Real de Madrid. A través de uno de estos documentos, fechado en 1809 y donde el escultor menciona a su familia, Tárraga determina que el hijo de Sancho que se dedicaría a su misma profesión, llamado Manuel Sancho según Ossorio y el Conde de la Viñaza, falleció tempranamente pues no aparece citado en dicho escrito.

AEA, LXXVIII, 2005, 312, pp. 397 a 412 
denomina Individuo de la Real Fábrica de la China en la Clase de Escultura ${ }^{85}$. Un año después, colaboraría en la decoración del templo de la Encarnación y en el túmulo realizado con motivo de las exequias de Carlos III, intervención que hubo de ser importante en proporción a las cantidades que se le abonaron ${ }^{86}$. En marzo de 1792 es nombrado por Carlos IV, Director del Ramo de Dibujo y Adornista de aquella Real Fábrica, encargándosele, también por estas mismas fechas, una colección de bajorrelieves. Posteriormente se sitúa su actividad en la Real Academia de Bellas Artes de San Fernando, donde en 1793 obtendría el primer premio de la primera clase de escultura ${ }^{87}$ y tres años después recibiría los honores de Académico de Mérito, como ya habían apuntado Ceán, Ossorio y el Conde de la Viñaza ${ }^{88}$. En abril de 1795 se le nombraría Escultor de Cámara ${ }^{89}$.

En 1807 Sancho estaba trabajando unas obras en marfil, material que parece utilizó con preferencia. Las siguientes noticias facilitadas por Tárraga emplazan al escultor en Sevilla en 1809, a donde, según Ossorio, habría huido tras la invasión francesa. Entre abril y mayo de 1810 se ordenan unos pagos a su favor por haber entregado unos bajorrelieves en marfil a la Suprema Junta Central del Consejo de Regencia de los Reinos de España e Indias ${ }^{90}$. En el mismo mes de mayo se documenta su presencia en San Fernando, lugar en el que hubo de realizar algún trabajo y desde donde vuelve a manifestar su alarmante situación económica, constante a lo largo de su vida, insistiendo en que se le pagase algo de lo que se le debía por la ejecución de los marfiles aludidos, pues aún no se le habían satisfecho los pagos. Según Tárraga, seguramente a causa de su preocupante posición Sancho aceptó el nombramiento de Director de Escultura de la Academia de Méjico, cargo que se le concedió en agosto de 1810 y del que tomó posesión en febrero del año siguiente ${ }^{91}$. Sin embargo, tampoco esta autora conoce más producción del artista en América que el encargo para erigir en 1820 el túmulo funerario de la Reina Doña María Isabel Francisca de Braganza, segunda esposa de Fernando VII. Por el contrario, refiere una serie de obras ejecutadas por el escultor en la Corte que no habían sido citadas con anterioridad, como los relieves en mármol para el Salón de Embajadores del Palacio, y de los que el propio Sancho haría el modelo, o los diseños para una serie de vasos hechos en la Real Fábrica de la China. En relación a los dos bajorrelieves en marfil que Ossorio y el Conde de la Viñaza sitúan en el Casino del Príncipe de El Escorial, concluye Tárraga -siguiendo un estudio de Estella Marcos - que podría tratarse de dos plaquetas que muestran unos Centauros u otros que representan La Guerra y La Victoria ${ }^{92}$. Sobre la intervención del artista en las fuentes del Prado que afirma Ceán, nada se menciona en los textos citados, no obstante, y como se ha podido comprobar, se hace evidente la necesidad de un análisis en profundidad sobre la actividad llevada a cabo por este artista tanto en España como en América, lugar en el que permaneció casi dos décadas y donde, con toda seguridad, ha de existir un número importante de obras realizadas de su mano.

\footnotetext{
${ }^{85} \mathrm{Ibidem}, \mathrm{p} .239$.

${ }^{86}$ Ibidem. Sancho recibiría 20.000 reales, sólo superado por Domingo Dalli, al que se abonarían 27.000 , frente a los 1.500 que percibió Manuel Adeba Pacheco.

${ }^{87}$ Ibídem. El tema representado llevaba por título: «Los señores de Vizcaya jurando los fueros de la provincia. Los vizcaínos reciben a Fernando el Católico bajo el árbol de Guernica».

${ }^{88} \mathrm{Ibidem}$. El relieve presentado con ocasión de su nombramiento mostraba el tema de la «Llegada de un soldado que presenta a David el brazalete y corona de Saúl; David rompe sus vestiduras y manda que maten al mensajero».

${ }^{89}$ Serrano Fatigati y Pardo Canalís habían situado este hecho en el mes de febrero (ver nota 82).

${ }^{90}$ Quizás aquellos que estaba trabajando en 1807.

${ }^{91}$ Tárraga Baldó, M. ${ }^{2} \mathrm{~L} .:$ «España y América...», Op. cit., p. 241.

${ }_{92}$ Ibidem, p. 242; Estella Marcos, M.: «Casita de EI Príncipe de E1 Escorial. Sala de los Marfiles», Reales Sitios, Madrid, n. ${ }^{\circ} 57,1978$, p. 62 .
}

AEA, LXXVIII, 2005, 312, pp. 397 a 412 